Supporting Information

for

\title{
Understanding the Interaction Mechanism between Elemental Selenium and Ferric Hydroxide in Wastewater Treatment
}

Jingyi Wang, Junmeng Li, Lei Xie, Qingxia Liu, and Hongbo Zeng*

Department of Chemical and Materials Engineering, University of Alberta, Edmonton, $A B$,

T6G 2V4, Canada

*E-mail: hongbo.zeng@ualberta.ca (H.Zeng) 


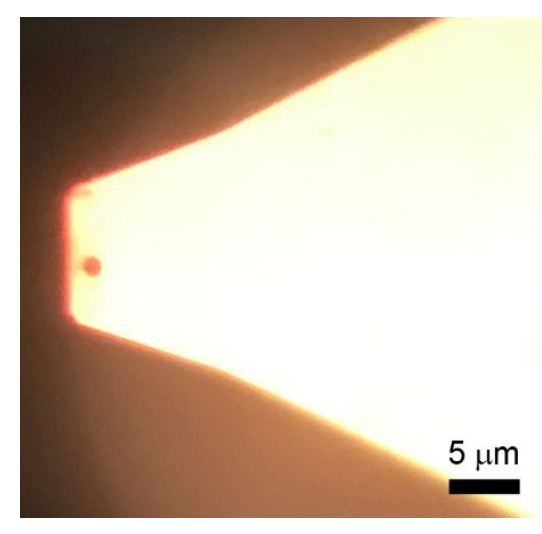

Figure S1. Optical microscopic image of a $\mathrm{Se}^{0}$ particle glued on an AFM cantilever

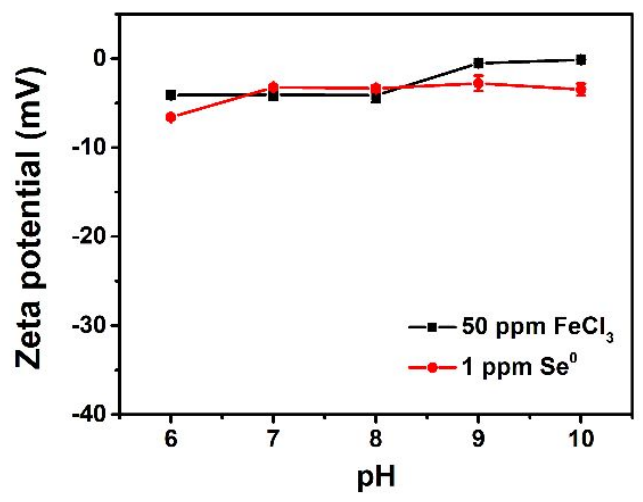

Figure S2. Zeta potentials of $50 \mathrm{mg} \mathrm{L}^{-1} \mathrm{FeCl}_{3}$, and $1 \mathrm{mg} \mathrm{L}^{-1} \mathrm{Se}^{0}$ particles as a function of $\mathrm{pH}$ in simulated wastewater.

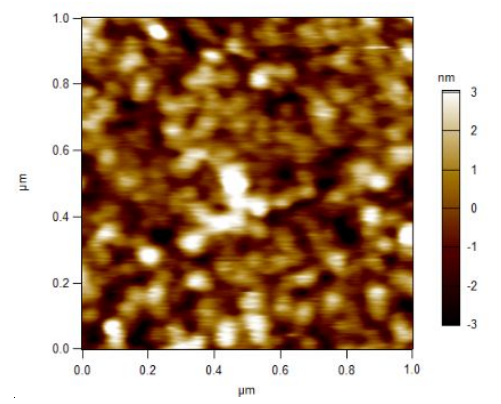

Figure S3. AFM topographic image of $\mathrm{Fe}(\mathrm{OH})_{3}$ surface in air. 

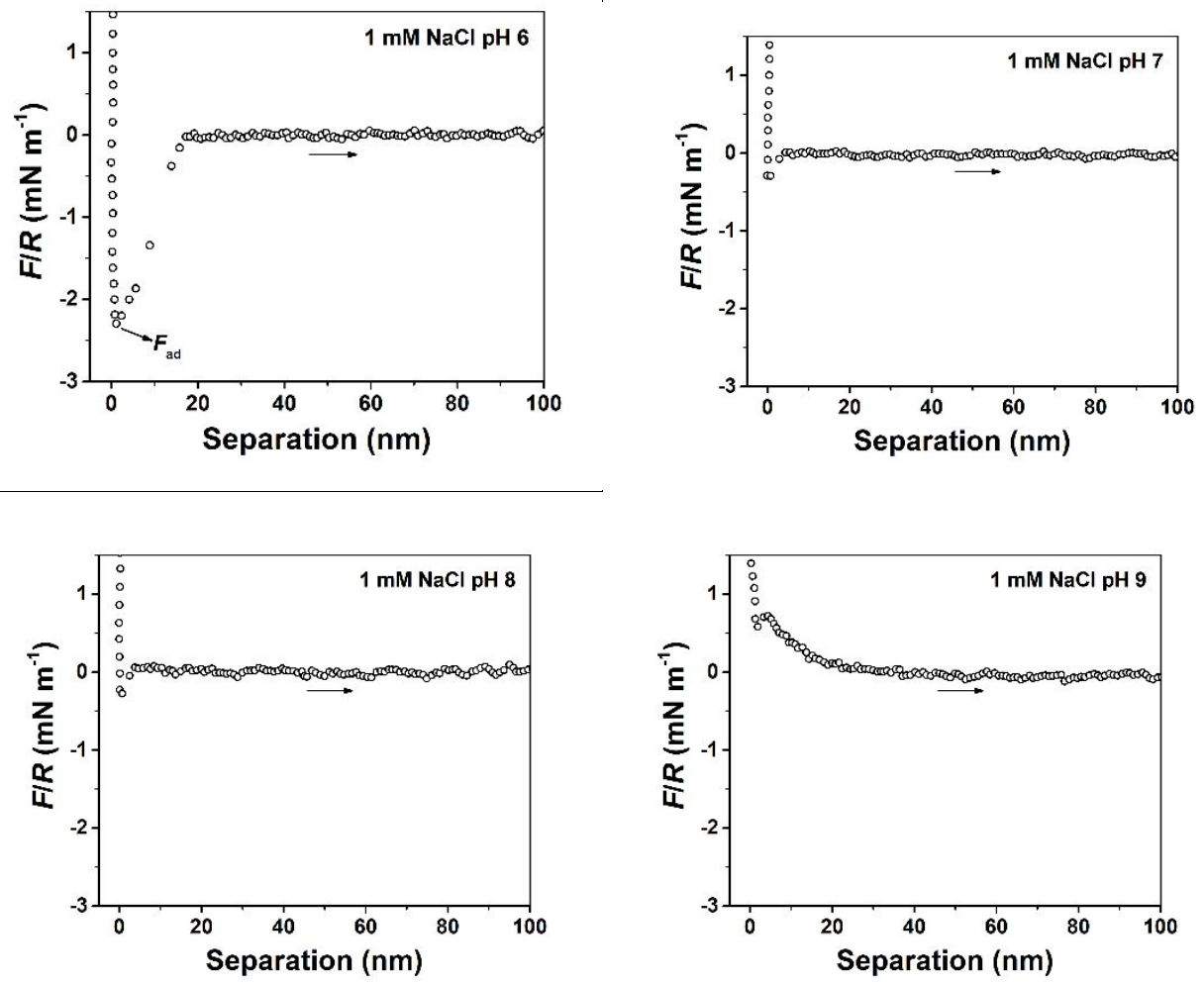

Figure S4. Typical retract force-separation curves of $\mathrm{Se}^{0}$ and $\mathrm{Fe}(\mathrm{OH})_{3}$ interaction in $1 \mathrm{mM} \mathrm{NaCl}$ at $\mathrm{pH} 6,7,8$ and 9 .

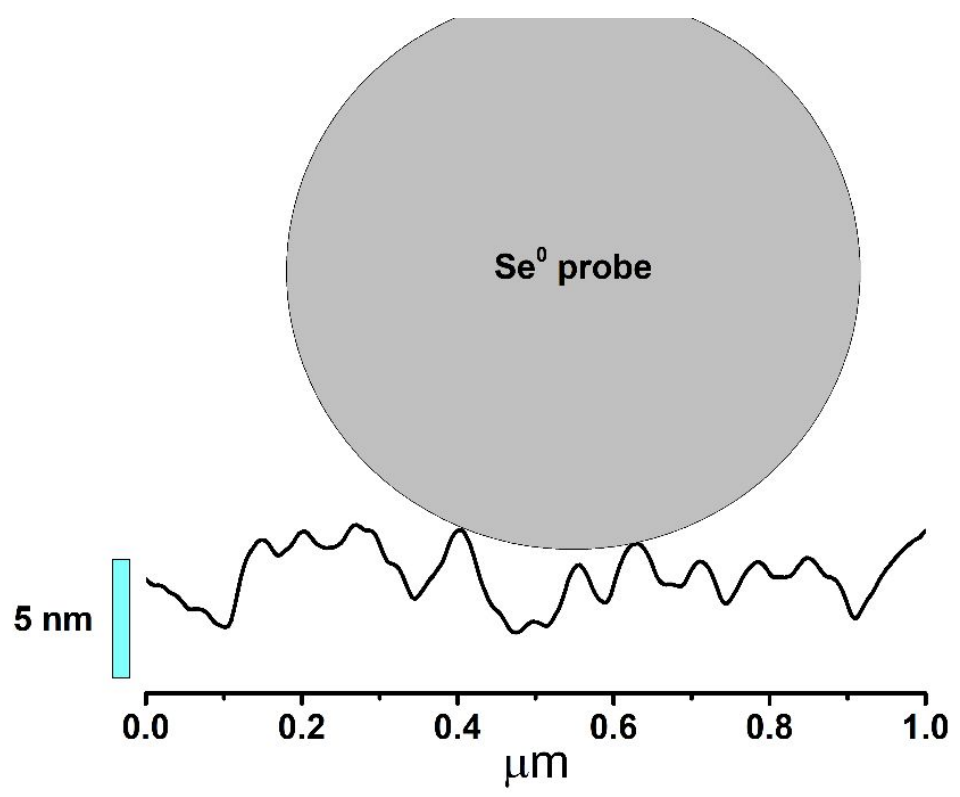


Figure S5. Line section of AFM topographic image in $1 \mathrm{mM} \mathrm{NaCl}$ at $\mathrm{pH}$. The schematic illustration of $\mathrm{Se}^{0}$ probe is placed above the section line to visually check that at some spots, especially the valleys, there will be no real contact between the probe and the surface.
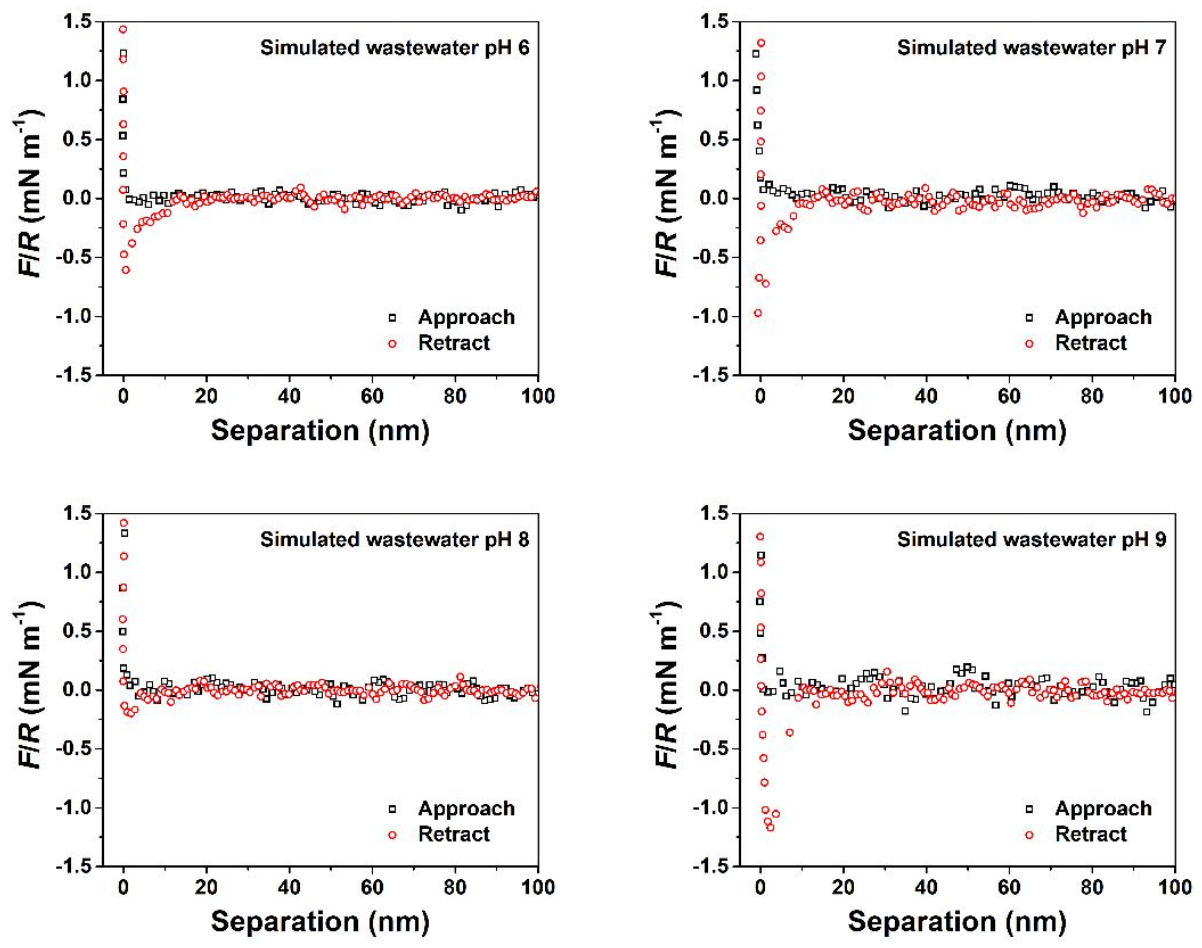

Figure S6. Typical approach force-separation curves of $\mathrm{Se}^{0}$ and $\mathrm{Fe}(\mathrm{OH})_{3}$ interaction in simulated wastewater at $\mathrm{pH} 6,7,8$ and 9. 

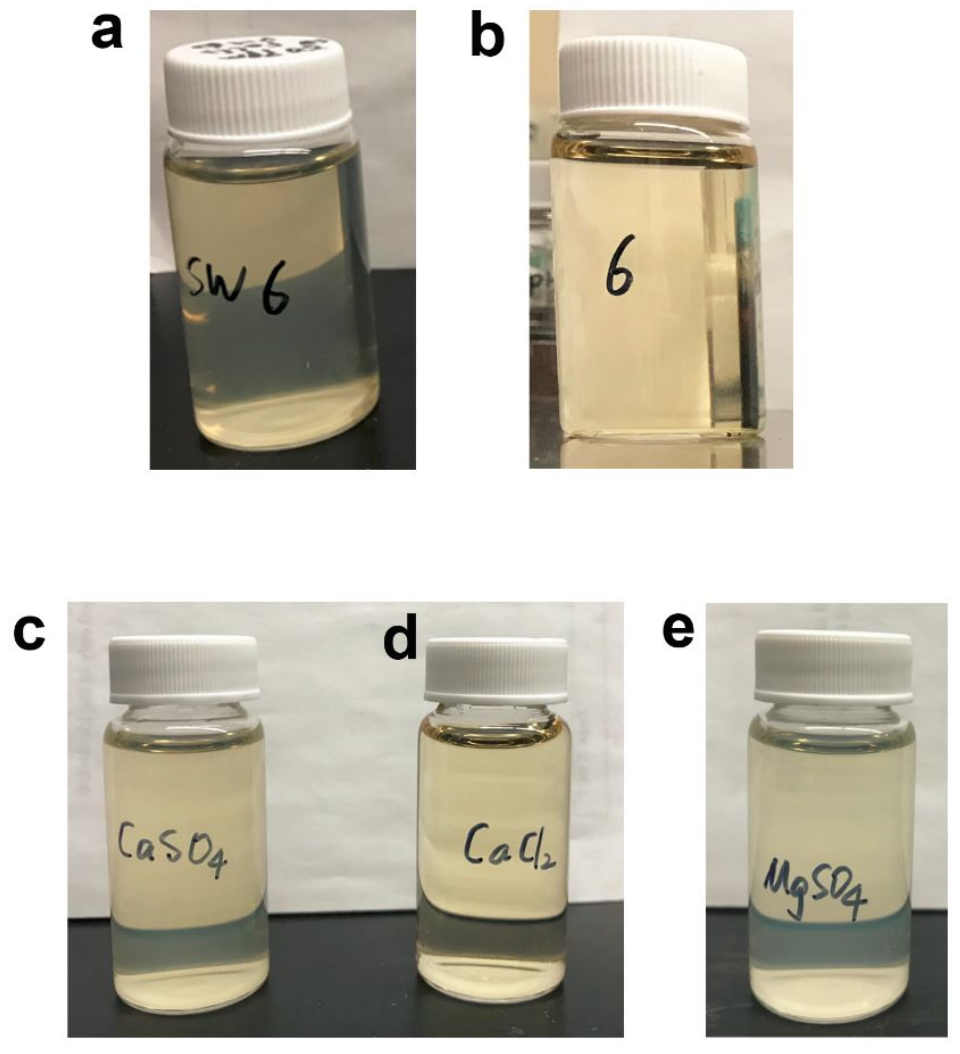

Figure S7. Photos of $50 \mathrm{mg} \mathrm{L}^{-1} \mathrm{FeCl}_{3}$ at $\mathrm{pH} 6$ in (a) simulated wastewater, (b) Milli-Q water, (c) $7.55 \mathrm{mM} \mathrm{CaSO}{ }_{4}+61.5 \mathrm{mM} \mathrm{NaCl}$, (d) $7.55 \mathrm{mM} \mathrm{CaCl}_{2}+69.1 \mathrm{mM} \mathrm{NaCl}$, and (e) $15.5 \mathrm{mM}$ $\mathrm{MgSO}_{4}+29.7 \mathrm{mM} \mathrm{NaCl}$.
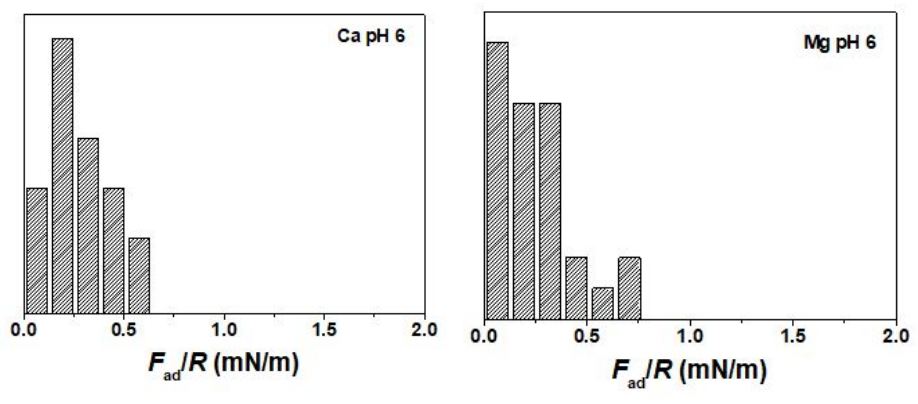

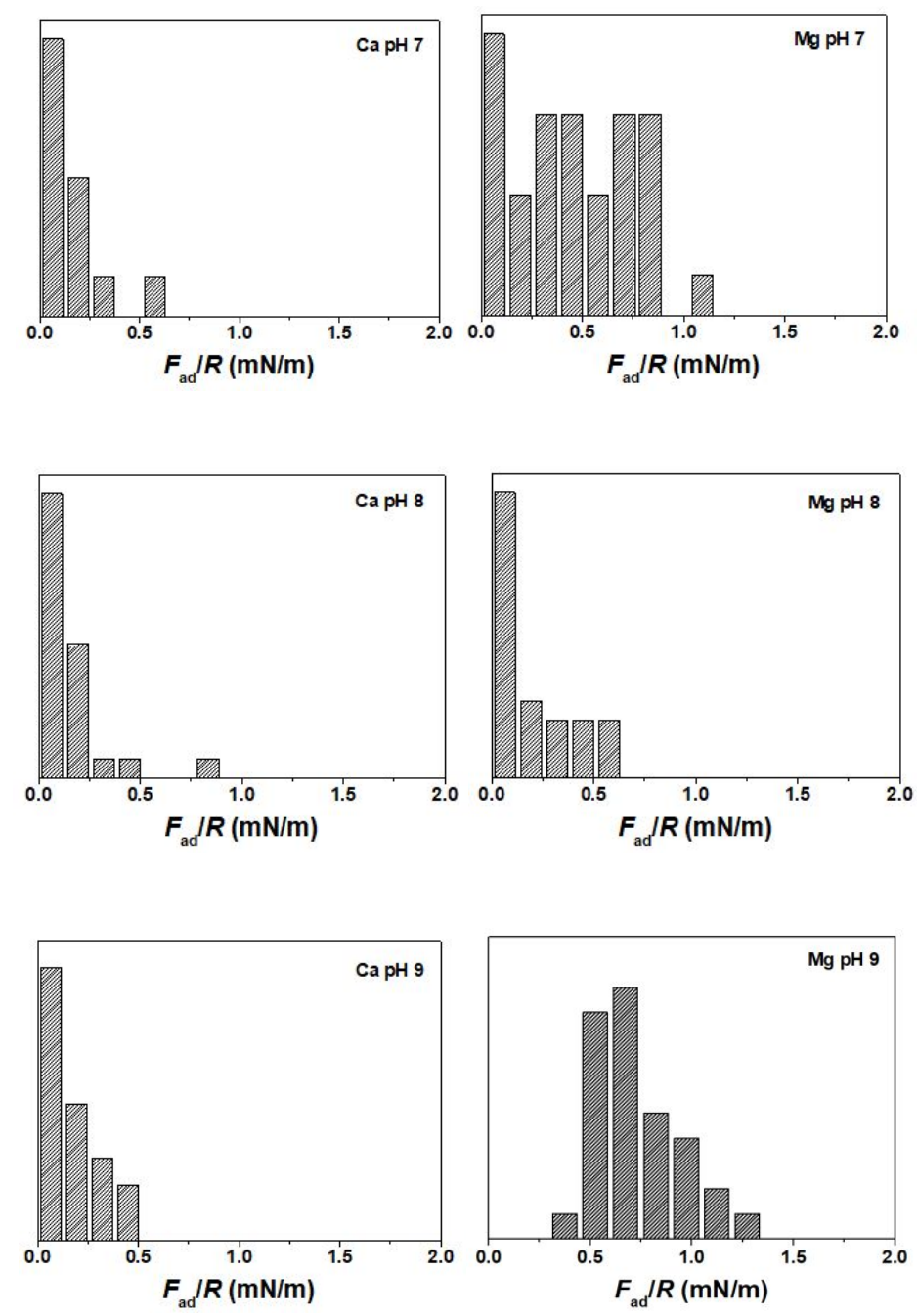

Figure S8. Adhesion histogram of $\mathrm{Se}^{0}$ and $\mathrm{Fe}(\mathrm{OH})_{3}$ interaction in $7.55 \mathrm{mM} \mathrm{CaSO}_{4}$ and $15.5 \mathrm{mM}$ $\mathrm{MgSO}_{4}$ solutions at $\mathrm{pH} 6,7,8$, and 9. The ionic strength of solutions were kept constant as 0.092 $\mathrm{M}$ by adding $\mathrm{NaCl}$. 